\title{
A sliding mode algorithm for antilock braking/traction control of EVs
}

- Minh Ngoc Vu

- Minh Cao Ta

Center for Technology Innovation, Hanoi University of Science and Technology, Vietnam

(Manuscript Received on July 15, 2015, Manuscript Revised August 30, 2015)

\begin{abstract}
This paper presents a slip suppression controller using sliding mode control method for electric vehicles which aims to improve the control performance of Evs in both driving and braking mode. In this method, a sliding mode controller is designed to obtain the
\end{abstract}

maximum driving force by suppressing the slip ratio. The numerical simulations for one wheel model under variations in mass of vehicle and road condition are performed and demonstrated to show the effectiveness of the proposed method.

Keywords: electric vehicle (EV); traction control; anti-lock braking system (ABS); sliding mode control.

\section{INTRODUCTION}

Electric vehicles (EVs) have become very attractive in replacing conventional internal combustion engine vehicles because of environmental and energy issues. They have received a great attention from the research community. Control methodologies have been actively developed and applied to EVs to improve the EVs performances [1-8]

Traction control of electric vehicles has drawn extensive attention since electric motors can produce very quick and precise torques compared to conventional internal combustion engines. In [3], traction control based on a maximum transmission torque estimation (MTTE) approach was proposed. The estimation was carried out by an open-loop disturbance observer. In [10], traction control of electric vehicles using a sliding-mode observer to improve the control performance and the energy conservation was presented. The controller against the model uncertainties is designed to obtain the maximum driving force by suppressing the slip ratio.

The anti-lock braking system (ABS) is the most important active safety system for road vehicles. The ABS can greatly improve the safety of a vehicle in extreme circumstances since it can maximize the longitudinal tire-road friction while keeping large lateral (directional) forces that ensure vehicle drive-ability [11]. At present, the ABS has become standard equipment for all new passenger cars in many countries.

As a key technology, regenerative braking is an effective approach to improve vehicle efficiency, and has been applied in various types of electric vehicles (EVs). However, the conventional friction braking system must be retained and works together with the regenerative braking system since the regenerative braking torque is limited by many factors, such as the 
motor speed, the state of charge (SOC) and temperature of the battery [9].

As it is well known, the control of the ABS is complicated. The main difficulty arising in the design of the ABS control is the strong nonlinearity and uncertainty. Standard ABS systems for wheeled vehicles equipped with traditional hydraulic actuators mainly use rulebased control logics. As a device with fast torque response, the advantage of the motor as an actuator has been realized by many researchers. A number of advanced control approaches have been proposed for the ABS, such as FLC [7], adaptive control [8], and antificial intelligencebase control. Sakai [1] compared the electric motor with the hydraulic brake system, and the advantage of the electric motor as an actuator is clarified by simulations considering the delay of actuator response.

This paper is organized as follows: A vehicle model for control design is introduced in Section 2, including the longitudinal vehicle model, the magic formula tire model, and a hydraulic brake system model. A sliding mode controller combining parameter adaptation approaches is proposed and the stability is proved in Section 3. The simulation results are presented and discussed in Section 4. Finally, conclusions are presented in Section 5.

\section{SYSTEM DESCRIPTION}

The structure of the braking system investigated in this paper is shown in Figure 1. The vehicle is considered to have four in-wheel motors. The hydraulic brake system consists of a brake pedal, a hydraulic control unit and four wheel cylinders and wheel speed sensors. When the brake is applied, the brake control unit calculates the required braking torque on the front and rear wheels according to the brake pedal stroke, and estimates the available motor braking torque according to vehicle velocity, battery and other information. On the base of the braking torque distribution algorithm, the demand motor torque is determined, and the brake control unit sends command signals to the motor control unit. The motor control unit decides the motor work or not to meet the demand on the motor torque, and transmits the actual motor braking torque signals to the brake control unit. The friction braking torque applied to the wheel is determined by the difference of the required braking torque to the wheel and the actual motor braking torque.

\subsection{Tire model}

The tire connects the external torques with the vehicle's longitudinal motion. The tire model includes empirical (semiempirical) and analytical models. Several models describing the nonlinear behavior of the tire have been reported in the literature, such as the Burckhardt model [9], LuGre tire model, and so on.

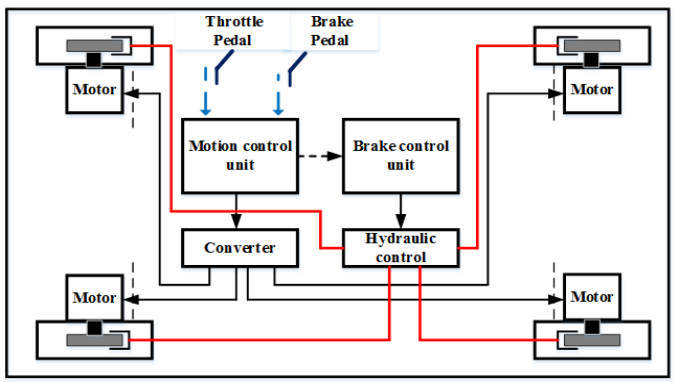

Figure 1. Configuration of the braking control system

In this paper, Magic Formula [12] is used, as it is particularly suitable for analytical purpose while retaining a good degree of accuracy in the description of the friction coefficient. During braking, the longitudinal slip ratio is defined as:

$$
l=\frac{w r-V}{\max (V, w r)}
$$

The tire driving force $\mathrm{F}$ is given by

$$
\begin{aligned}
& F_{d}=n(k, l) N \\
& N=m g
\end{aligned}
$$


Where $\lambda$ is the slip ratio; and $\omega$ is the angular speed of the wheel. The slip ratio of $\lambda=1$ characterizes the wheel is completely skidding when driving, the slip ratio of $\lambda=-1$ characterizes the wheel is completely skidding when braking. If the slip ratio gets the value $\lambda=0$, no skidding is happening at the point of contact of tire with road.

$\lambda$, which is called Magic-Formula and given in [12] by

$$
\begin{array}{ll}
m(k, l)=-1.05 k^{*}\left(e^{-45 l}-\mathrm{e}^{-0.45 l}\right) & l>0 \\
m(k, l)=1.05 k *\left(e^{-35 l}-\mathrm{e}^{-0.35 l}\right) & l £ 0
\end{array}
$$

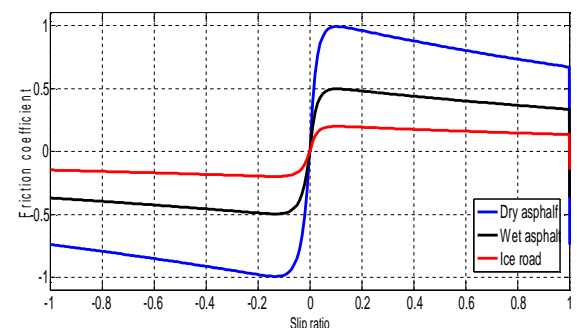

Figure 2. Relationship between slip ratio and friction coefficient

Fig 2 shows the relationship between friction coefficient $\mu$ and slip ratio $\lambda$ on the road surface conditions for dry asphalt $(\mathrm{k}=1)$, wet road $(\mathrm{k}=0.5)$ and ice road $(\mathrm{k}=0.2)$.

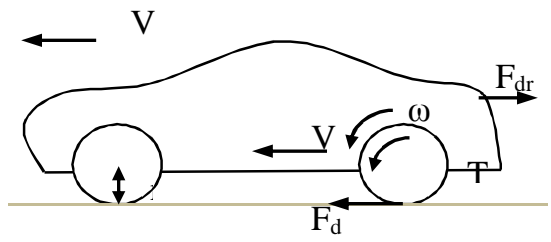

Figure 3. One wheel model

The friction coefficient $m(k, l)$ is a function of road surface condition coefficient $\mathrm{k}$ and slip ratio.

From Fig 2, evaluating the values of $\lambda$ which maximizes $m(k, l)$ for different $\mathrm{k}$ means to find the

value of $\lambda$ where the maximum value of the function $m(k, l)$ can be obtained. Let

$$
\frac{d}{d l} m(l)=0
$$

Equation (5) gives $l \gg 0.13$
Accordingly, for different road conditions, when $l \gg 0.13$ is met, the maximum braking force can be taken.

\subsection{Vehicle Model}

A vehicle model which is a propriate for acceleration on the longitudinal direction is described here. For simplicity, one wheel model directly driven by an electric motor is used for the derivation of control law and numerical simulations. Although the one wheel model is quite simple, it still retains the essential dynamics of the system.

In deriving the dynamic equations of the system, the lateral and vertical motions are neglected. A simple one wheel model is shown in Figure 3.

The dynamic equation are given by

$$
\begin{aligned}
& J \dot{w}=T_{w}-r F_{d} \\
& m \dot{V}=F_{d}-F_{d r} \\
& V_{\mathrm{w}}=r w \\
& F_{d r}=F_{r r}+F_{a r}
\end{aligned}
$$

Where $\omega$ is the angular velocity of wheel and $\mathrm{V}$ the vehicle body speed. Other parameters are defined in Table 2.

\subsection{Hydraulic Brake System}

In most EVs or HEVs, regenerative braking is generally used with hydraulic braking system.

The braking torque on each wheel depends on the hydraulic pressure of wheel cylinder. In addition, the hydraulic pressure of wheel cylinder can be changed through the coordinative control of the inlet valve and the outlet valve. The operation of an antilock braking system is a constantly switching process of there brake pressure. Therefore, a transport time delay between the demand and the actual brake pressure inevitably exists in the hydraulic line. On the 
contrary with the hydraulic brake system, the time response of the motor is very fast, and the torque control is very precise that will improve the vehicle antilock function. The performance of the electric motor with hydraulic brake system as an actuator of antilock brake system is compared in [10]. Now, the studies on the antilock brake system with the electric motor as actuators are becoming more and more popular.

In the next part of this paper, the dynamic model of hydraulic fluid lag of brake system is used as the following first order transfer function:

$$
G(s)=\frac{k}{t s+1}
$$

Where $\mathrm{k}$ is the gain of the hydraulic system, $\tau$ is the hydraulic torque time constant.

\subsection{Regenerative Braking Algorithm}

As an actuator of braking, the motor can not only convert the braking energy, but also has rapid and precise torque response. The motor braking torque is limited by several factors. Therefore, regenerative braking must be carried out together with the friction braking in EVs. For the brake system of EVs, an algorithm is required to decide on how to distribute the braking force between regenerative braking and friction braking in normal braking or emergency braking situations.

Fig 4 shows that, if the maximum motor braking torque $T_{\max }$ is less than the required braking torque $\mathrm{T}_{\mathrm{br}}$, then both the motor and friction brake system will work in union. The motor braking torque will be used to its maximum level. The difference between the required braking torque and the actual motor torque will be provided by friction brake system. If the maximum motor braking torque $\mathrm{T}_{\max }$ is more than the required braking torque $\mathrm{T}_{\mathrm{br}}$, then only motor brake will carry out the job, and the motor controller regulates the current input to ensure the required braking torque.

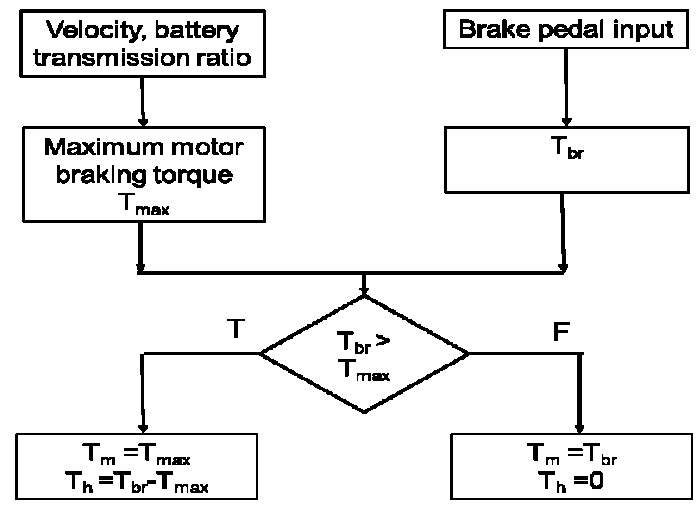

Figure 4. Flow chat of regenerative braking

\section{SLIDING MODE CONTROL}

For slip ratio control, a nonlinear controller using SMC with integral action is proposed. Without loss of generality, the control law is derived based on the one wheel model mentioned above. The differentiation of equation (1) is

$$
\dot{\lambda}= \begin{cases}\frac{(1-\lambda) r \dot{\omega}-\dot{V}}{r \omega} & \lambda>0 \\ \frac{(1-\lambda) \dot{V}-r \dot{\omega}}{V} & \lambda \leq 0\end{cases}
$$

Equations (11) can be rewritten as:

$\dot{\lambda}= \begin{cases}\psi_{d}+\rho_{d} T_{w} & \lambda>0 \\ \psi_{b}+\rho_{b} T_{w} & \lambda \leq 0\end{cases}$

where $T_{w}$ is the control input.

$T_{w}=T_{m}+T_{h}$

In braking mode $\mathrm{T}_{\mathrm{h}}<0, \mathrm{~T}_{\mathrm{m}}<0$.

In driving mode $T_{h}=0, T_{m}>0$

Substituting equations (6), (7), to (11) (12) and ignoring the rolling resistance and air resistance, the following equations can be obtained

$$
\begin{gathered}
\psi_{d}=-\frac{g}{V_{w}}\left[1+(1-\lambda) \frac{m r^{2}}{J}\right] \mu(k, \lambda) \\
\psi_{b}=-\frac{g}{V}\left[\lambda-1-\frac{m r^{2}}{J}\right] \mu(k, \lambda)
\end{gathered}
$$




$$
\begin{gathered}
\rho_{d}=\frac{(1-\lambda) r}{J V_{w}} \\
\rho_{b}=-\frac{r}{J V}
\end{gathered}
$$

Actually, the mass of vehicle often changes with the number of passengers and vehicle always travels on various kinds of road surfaces. The normal loads on the front and rear wheel often changes. As a result, the controller needs to perform much robustly with the uncertainties affecting on the mass of vehicle and road surface condition which are represented by $m$. The ranges of variation in $m$ are set as

$$
M_{\text {min }} \leq m \leq M_{\max }
$$

In equation (14) the nonlinear function $\psi$ is not exactly known, but it can be estimated as $\hat{\psi}$. By using equation (12) the estimation of $\psi$ can be defined as

$$
\widehat{\psi}= \begin{cases}-\frac{g}{V_{w}}\left[1+(1-\lambda) \frac{\hat{M} r^{2}}{J}\right] \mu(k, \lambda) & \lambda>0 \\ -\frac{g}{V}\left[\lambda-1-\frac{\hat{M} r^{2}}{J}\right] \mu(k, \lambda) & \lambda \leq 0\end{cases}
$$

We define the estimated values of these parameters respectively by using the arithmetic mean of the value of the bounds as

$$
\begin{gathered}
\widehat{M}=\frac{M_{\text {min }}+M_{\max }}{2} \\
\left|\psi_{i}-\widehat{\psi}\right| \leq\left|\psi_{i_{\text {max }}}-\widehat{\psi}\right|
\end{gathered}
$$

Where $\mathrm{i}=\mathrm{d}$ or $\mathrm{b}$

The error in estimation can be given by

Then, we let

$$
\Phi= \begin{cases}\frac{g r^{2}(1-\lambda)}{2 J V_{w}} M_{t b} \mu(k, \lambda) & \lambda>0 \\ \frac{g r^{2}}{2 J V}\left(M_{t b} \mu(k, \lambda)\right. & \lambda \leq 0 \\ M_{t b}=M_{\text {max }}-M_{\text {min }} & \end{cases}
$$

As shown in Fig 2, the braking effort coefficient varies significantly, depending on the road condition. The goal of the ABS is to take full advantage of the peak braking effort coefficient, which can be achieved by maintaining the slip ratio between 0 and 0.13 . Although the direct slip ratio measurement is difficult, many researchers have proposed various algorithms on the estimation of the slip ratio [3].

In order to have the slip ratio $\lambda$ track the desired slip ratio $\lambda^{*}$, the sliding function of conventional SMC will be defined as:

$$
S=\lambda^{*}-\lambda
$$

$\lambda$ is actual slip ratio and $\lambda^{*}$ is reference value

In order to achieve convergence from arbitrary initial values, a switching control law is: $\dot{S}=-\varepsilon \operatorname{sgn}(\mathrm{S})-K_{i} S \quad \varepsilon>0, K_{i}>0$

Where $\varepsilon$ and $\mathrm{K}_{\mathrm{i}}$ are positive constants; and $\operatorname{sgn}(\mathrm{S})$ is a sign function, which is defined as

$$
\operatorname{sgn}(S)= \begin{cases}1 & S>0 \\ 0 & S=0 \\ -1 & S<0\end{cases}
$$

Differentiating equation (24) gives

$$
\dot{S}=\dot{\lambda}^{*}-\dot{\lambda}=-\varepsilon \operatorname{sgn}(\mathrm{S})-K_{i} S
$$

The reference slip ratio $\lambda^{*}$ is a constant, thus $\dot{\lambda}^{*}=0$. Substituting (12) into (27) gives

$$
-\psi_{i}-\rho_{i} T_{w}=-\varepsilon \operatorname{sgn}(\mathrm{S})-K_{i} S
$$

Where $\mathrm{i}=\mathrm{d}$ or $\mathrm{b}$, denoting the variable of driving or braking. 
Substituting (16), (17) into (28) gives

$$
T_{w}=\frac{1}{\rho_{i}}\left(-\psi_{i}+\varepsilon \operatorname{sgn}(S)+K_{i}\left(\lambda^{*}-\lambda\right)\right)
$$

Then the estimate of control input can be obtained as

$$
\hat{T}_{w}=\frac{1}{\rho_{i}}\left(-\hat{\psi}+\varepsilon \operatorname{sgn}(S)+K_{i}\left(\lambda^{*}-\lambda\right)\right)
$$

The sliding gain $\varepsilon$ is chosen as

$$
\varepsilon=\Phi+\eta
$$

With $\eta$ is a strictly positive constant.

By choosing a Lyapunov function as

$$
V=\frac{1}{2} S^{2}
$$

And differentiating (32) with respect to time, that gives

$$
\dot{V}=\frac{1}{2} \frac{d}{d t} S^{2}=S \dot{S}
$$

Substituting (12), (22), (23) into (33) gives

$$
\dot{V}=S\left[\left(\psi_{i}-\hat{\psi}\right)-\varepsilon \operatorname{sgn}(S)-K_{i}\left(\lambda^{*}-\lambda\right)\right]
$$

$$
\begin{aligned}
\dot{V} & \leq S\left[\Phi-\varepsilon \operatorname{sgn}(S)-K_{i}\left(\lambda^{*}-\lambda\right)\right] \\
& \leq \Phi|S|-(\Phi-\eta)|S| \\
& \leq-\eta|S|
\end{aligned}
$$

It can be proved, that (35) satisfies the sliding condition $\dot{V}<0$ whenever $\left(\lambda^{*}-\lambda\right)$ reverses its sign. Therefore, the system is asymptotically stable.

In design of sliding mode control system, the switched control law requires switching at an infinite frequency. However, because the actuators have time delays and other imperfections, the action can lead to chatter in a neighborhood of the sliding surface. To reduce the chattering, can be using the saturation function. Equations (28) can be rewritten as:

$$
T_{w}=\frac{1}{\rho}\left(-\psi+\varepsilon \operatorname{s} a t\left(\frac{S}{\Phi}\right)+\alpha\left(\lambda^{*}-\lambda\right)\right)
$$

Where $\phi>0$ is a design parameter representing the width of the boundary layer around the sliding surface and the saturation function is defined as

$$
\operatorname{sat} \frac{S}{\Phi}=\left\{\begin{array}{l}
\frac{S}{\Phi}-\Phi \leq S \leq \Phi \\
\operatorname{sgn}\left(\frac{S}{\Phi}\right) \quad \text { otherwise }
\end{array}\right.
$$

\section{SIMULATION AND DISCUSSION}

To evaluate the performance of the proposed SMC and different actuator, simulations were implemented in MATLAB/SIMULINK. Most of the model parameters used in the simulations are listed in Table 1.

Fig 5 shows that the responses of slip ratio with different masses can converge to the reference value under the variation in the road condition. It is known that when the mass gets the nominal value $1200(\mathrm{~kg})$ the response is more accurately than the car with other masses. The variation in the mass of the car is made by assigning the value of $\mathrm{m}(1000 \mathrm{~kg}$ to $1400 \mathrm{~kg})$. The vehicle was brought to a steady longitudinal velocity of $26 \mathrm{~m} / \mathrm{s}(94 \mathrm{~km} / \mathrm{h})$ along a straight path and then the ABS was applied on the wheel. From $5 \mathrm{~s}$ to $6 \mathrm{~s}$, the car travels on the dry asphalt, from $6 \mathrm{~s}$ to $7 \mathrm{~s}$ the car travels on the wet asphalt. The the value of reference slip ratio $\lambda^{*}$ is set 0.1 . Fig 6 shows that the responses of slip ratio with value of reference slip ratio $\lambda^{*}$ is set 0.13 .

Table1. Parameters used in the simulations

\begin{tabular}{ccc} 
Vehicle & $\mathrm{m}$ & $1200 \mathrm{~kg}$ \\
\cline { 2 - 3 } & $\mathrm{R}$ & $0.26 \mathrm{~m}$ \\
\hline \multirow{2}{*}{ Motor } & $\mathrm{J}$ & $13.15 \mathrm{~kg} . \mathrm{m} 2$ \\
\cline { 2 - 3 } & $\mathrm{T} \max$ & $500 \mathrm{Nm}$
\end{tabular}

Next, the simulation time is set to $16 \mathrm{~s}$ in all. There are four phases in the simulations as follows. The first phase, the time is from $0 \mathrm{~s}$ to $8 \mathrm{~s}$ 
the car travels on the wet asphalt in drive mode. The second phase, from $8 \mathrm{~s}$ to $10 \mathrm{~s}$, the car travels on the ice road. The third phase, from $10 \mathrm{~s}$ to $12 \mathrm{~s}$, the car travels on ice road in brake mode. The last phase, the car runs on wet asphalt during $12 \mathrm{~s}$ to 16s. $\mathrm{Ki}=10$ and $\eta=1$. Since many researchers have proposed various algorithms about the estimation of the optimal slip ratio, to simplify the problem, the slip ratio 0.13 will be adopted in simulations.

Fig 7 shows the wheel speed and vehicle velocity with the SMC controller. Fig 9 illustrates the comparison slip ratio with SMC and bangbang controller. Fig 8 illustrates the comparison velocity of vehicle with SMC and bang-bang controller. As can be seen, the SMC controller try to stop the car quickly and keep the slip ratio at the optimal value.

Comparing to the bang-bang ABS system, the SMC controller produces smoother variation in wheel rotational speed and the slip ratio, thereby improving braking stability and passenger comfort. The erformance of the ABS with the SMC controller is far better than the ones with the Bang-bang based controller.

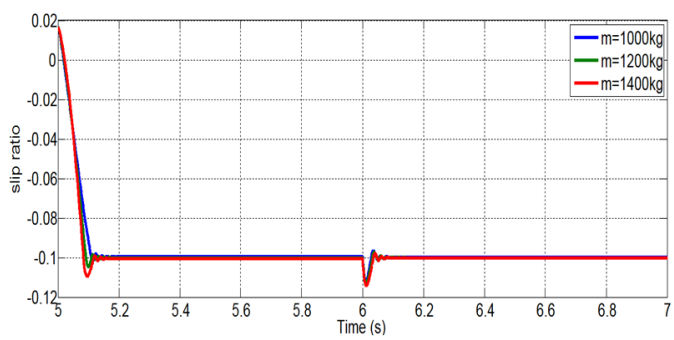

Figure 5. Slip ratio with variation of mass

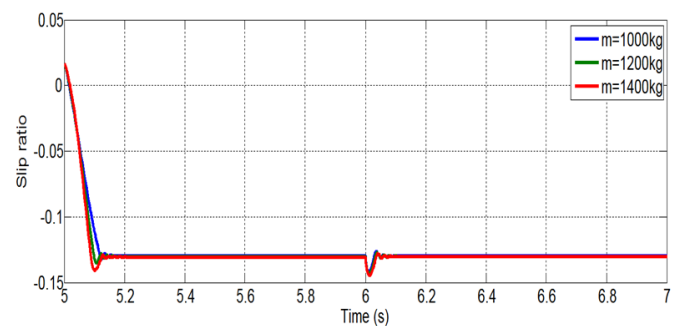

Figure 6. Slip ratio with variation of mass

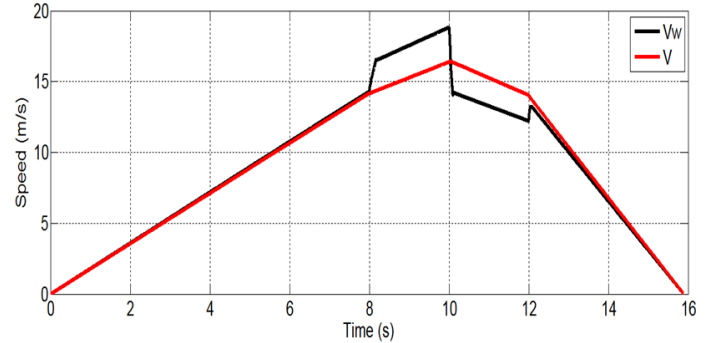

Figure 7. Wheel speed with SMC

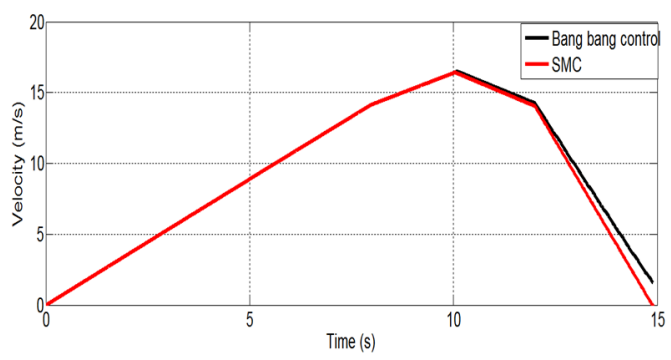

Figure 8. Vehicle speed with SMC and bang-bang controller

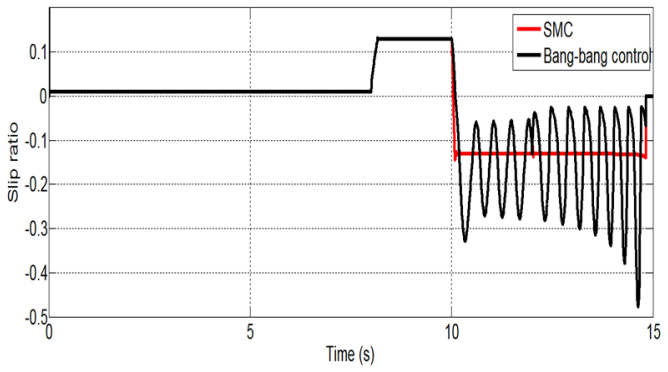

Figure 9. Slip ratio with SMC and bang-bang controller

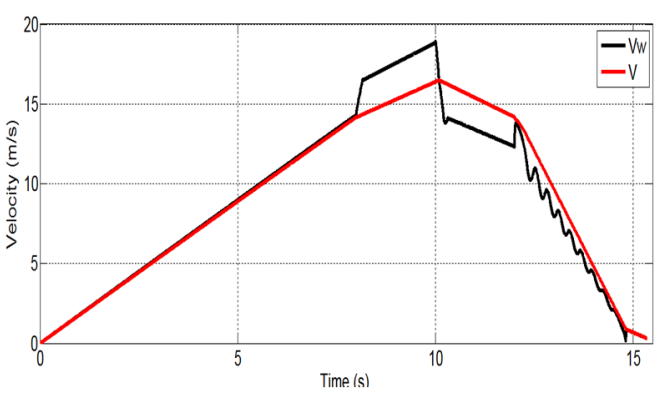

Figure 10. Vehicle speed in distribution of braking

\section{Trang 180}




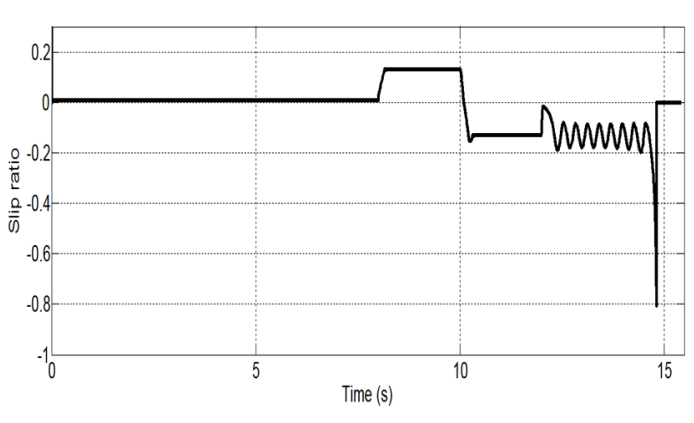

Figure 11. Slip ratio in distribution of braking

Table 2. Parameters used in the simulations

\begin{tabular}{|c|c|c|}
\hline Symbols & Unit & Description \\
\hline $\mathbf{J}$ & $\mathrm{kg} \cdot \mathrm{m}^{2}$ & Wheel inertia \\
\hline $\mathrm{V}_{\mathrm{w}}$ & $\mathrm{m} / \mathrm{s}$ & Wheel velocity \\
\hline$\omega$ & $\mathrm{Rad} / \mathrm{s}$ & Wheel rotation \\
\hline $\mathrm{T}_{\mathrm{w}}$ & $\mathrm{Nm}$ & Driving/Braking torque \\
\hline $\mathrm{T}_{\mathrm{m}}$ & $\mathrm{Nm}$ & Motor torque \\
\hline $\mathrm{T}_{\mathrm{h}}$ & $\mathrm{Nm}$ & Hydraulic torque \\
\hline $\mathrm{r}$ & $\mathrm{m}$ & Wheel radius \\
\hline $\mathrm{F}_{\mathrm{d}}$ & $\mathrm{N}$ & Friction force \\
\hline $\mathrm{m}$ & $\mathrm{kg}$ & Vehicle mass \\
\hline $\mathrm{V}$ & $\mathrm{m} / \mathrm{s}$ & Chassis velocity \\
\hline$\lambda$ & & Slip ratio \\
\hline$\mu$ & & Friction Coefficient \\
\hline $\mathrm{F}_{\mathrm{rr}}$ & $\mathrm{N}$ & Rolling resistance \\
\hline $\mathrm{F}_{\mathrm{ar}}$ & $\mathrm{N}$ & Air resistance \\
\hline
\end{tabular}

As can be seen from the Fig 10, the maximum motor braking torque Tmax $=300 \mathrm{Nm}$. From $10 \mathrm{~s}$ to $12 \mathrm{~s}$, the car travels on the ice road only motor brake will carry out the job, and the motor controller regulates the current input to ensure the required braking torque. From $12 \mathrm{~s}$ to $15 \mathrm{~s}$ the car travels on the ice road, both the motor and friction brake system will work in union. Fig 11 is slip ratio of $\mathrm{EV}$ in distribution of braking.

\section{CONCLUSIONS}

This paper has proposed a slip suppression controller using sliding mode control method for electric vehicles which aims to improve the control performance of Evs in both driving and braking mode. Simulation models of vehicle, actuators and controller were set up in MATLAB/SIMULINK.

The simulation results show that, SMC controller works well in both driving mode and braking mode. Compared with a conventional bang-bang ABS controller, the braking performance of the vehicle has been improved with the proposed SMC controller, the chattering phenomenon is reduced effectively.

\section{ACKNOWLEDGMENT}

This study was Supported by The State Granted Project KC03.08/11-15: "Design of Control System And Drive For Electric Vehicles”.

\section{Thuật toán điều khiển trượt chống bó phanh/điều khiển lực kéo ô tô điện}

\section{- Vũ Ngọc Minh}

- Tạ Cao Minh

Trung tâm sáng tạo và công nghệ, Đại học Bách Khoa Hà Nội, Việt Nam 


\section{TÓM TÁT}

Bài báo trình bày một bộ điều khiển chống trượt cho ô tô điện sử dụng phương pháp điều khiển trượt nhằm nâng cao hiệu quả kiểm soát của ô tô trong cả hai chế độ chạy xe và phanh xe. Trong phương pháp này, bộ điều khiển trượt được thiết kế để có

lực kéo tối đa bằng cách giới hạn tỉ lệ trượt. Các kết quả mô phỏng áp dụng trên mô hình xe một bánh hoạt động trong các điều kiện khác nhau của mặt đường cũng như sự thay đổi khối lượng xe đã chứng minh cho thấy hiệu quả của phương pháp được đề xuất.

Từ khóa: ô tô điện (EV); điều khiển lực kéo; hệ thống chống bó phanh (ABS); điều khiển trượt.

\section{REFERENCES}

[1]. Sakai, S.; Sado, H.; Hori, Y. Anti-skid control with motor in electric vehicle. In Proceedings of the 6th International Workshop on Advanced Motion Control, Nagoya, Japan, 30 March-1 April 2000; pp. 317-322

[2]. Shin-ichiro Sakai and Yoichi Hori, Advantage of Electric Motor for Anti Skid Control of Electric Vehicle, EPE Journal, Vol.11, No.4, pp.26-32, 2001.

[3]. Dejun Yin and Yoichi Hori, A Novel Traction Control without Chassis Velocity for Electric Vehicles, World Electric Vehicle Journal, Vol. 3 - ISSN 2032-6653, 2009.

[4]. Cem Ünsal and Pushkin Kachroo, Sliding Mode Measurment Feedback Control for Antilock Braking System, IEEE Transactions on Control Systems Technology, Vol. 7, No. 2, pp.271-281, 1999.

[5]. F. Yu, J.Z. Feng and J. Li, A Fuzzy Logic Controller Design for Vehicle ABS with an On-Line Optimized Target Wheel Slip Ratio, International Journal of Automotive Technology, Vol. 3, No. 4, pp. 165-170, 2002.

[6]. Shinya Kodama, Lianbing Li and Yoichi Hori. Skid Prevention for EVs based on the Emulation of Torque Characteristics of Separately-wound DC Motor, in Proc. The 8th IEEE International Workshop on Advanced
Motion Control, Kawasaki, Japan, 2004, pp.75-80.

[7]. Mirzaei, A. Moallem, M. Dehkordi, B. Design of an optimal fuzzy controller for antilock braking systems. IEEE Trans. Veh. Technol. 2006, 55, 1725-1730.

[8]. Yu, J.S. A robust adaptive wheel-slip controller for antilock brake system. In Proceedings of the 36th IEEE Conference on Decision and Control, San Diego, CA, USA, 10-12 December 1997, Volume 3, pp. 2545-2546.

[9]. Jingang Guo, Xiaoping Jian and Guangyu Lin, Performance Evaluation of an Anti-Lock Braking System for Electric Vehicles with a Fuzzy Sliding Mode Controller, Energies 2014, 7, pp.6459-6476

[10].Shaobo Li,Tohru Kawabe, Slip Suppression of Electric Vehicles Using Sliding Mode Control Method, Intelligent Control and Automation, 2013, 4, pp.327-334

[11].Sergio, M.S Mara, T. Active Braking Control Systems Design for Vehicles, Springer, London, UK, 2010; pp. 3-17

[12].H. B. Pecejka and E. Bakker, The Magic Formula Tyre Model, Proceedings of the 1st International Colloquium on Tyre Models for Vehicle Dynamics Analysis, Vol. 21, Suppl. 001, 1991, pp. 1-18.

\section{Page 182}

